$\xi=-1$

\title{
A Proposal for observing Conceived Ladies having High Risk of Premature Delivery using WHSN
}

\author{
Radhika Rani Chintala ${ }^{1}$, Narasinga Rao M R ${ }^{2}$, Somu Venkateswarlu ${ }^{3}$ \\ ${ }^{1}$ Department of CSE, KLEF, Vaddeswaram, Guntur, Andhra Pradesh, India \\ ${ }^{2}$ Department of CSE, KLEF, Vaddeswaram, Guntur, Andhra Pradesh, India \\ ${ }^{3}$ Sreyas Institute of Engineering and Technology, Hyderabad, Andhra Pradesh, India \\ *Corresponding author E-mail: radhikarani_cse@kluniversity.in
}

\begin{abstract}
Premature delivery of baby leads to death of babies below the age of 5 years. Even if they survive, they have to leave with a permanent disability like loss of vision, reduced learning abilities and hearing problems. Over the past years researchers have noticed that, observing uterine contractions can help in assessing the advancement of pregnancy and health of baby. It also decides whether pregnant lady is in the process of giving birth and thus accordingly reduce the impacts of premature delivery. This paper proposes a simple, secure, comfortable and cheaper system to screen pregnant ladies who are vulnerable to premature delivery. This system comprises of a wireless Human Sensor Network (HSN) for non-obtrusively observing the uterine contractions and if it is observed that readings are outer the normal limits, then a warning alert is send via a smart device. This paper also proposed a proof-of-idea model and tried it for testing the performance, power utilization and quality of the system.
\end{abstract}

Keywords: Human sensor network, WHSN, Premature delivery, EHG, Uterine contractions.

\section{Introduction}

As per the observations made by [1] every year, about 1.5 crore children are delivered prematurely in the entire world. As per the study, prematurity is the point at which an infant is conceived before finishing 37 weeks in mother's womb [2]. The premature birth babies will suffer from severe health problems and which leads to their death [3]. It is observed that nearly 10 lakhs of babies under 5 years [4], are being died in the world per year, due to their premature birth. Those premature babies who survive an untimely birth generally experience the lifelong health problems like loss of vision, reduced learning abilities and hearing problems [1,5].

Around the world, in under developing countries half of premature delivered babies $(<32$ weeks) are losing their lives due to the shortage of proper medical services. On the other side, in highly developed countries every one of them survives. Besides, the percentage of premature births isn't diminishing. In the United States and Europe, the percentage of premature deliveries has gone up from $9 \%$ to $13 \%$ since 1980's [6]. Despite the fact that premature delivery is an entire world issue, more than $59 \%$ of these premature deliveries occurs in under developing countries [1].

\subsection{Reasons for Premature Delivery of Babies}

The premature births take place because of several reasons. Most of the reasons are not properly understood \& defined [1,7]. The past medical history of the pregnant lady and her family history, like her parents having premature delivery, may be one of the main reasons [4]. The premature delivery is a difficult issue in medicinal services frameworks [2]. The families are spending at about 500 crores of rupees per year on medicinal expenses of premature deliveries $[3,5,6]$.

\subsection{Elucidations of Premature Births}

The researches carried on the reasons causing the premature delivery, proposed that with a useful and financially savvy mind; more than seventy five percent of the children conceived prematurely can survive. As per [8], uterine contractions are a vital estimation in observing pregnant lady. It also helps in assessing the wellbeing and pregnancy progress of a lady. It will also help in deciding whether the pregnant lady is in the process of giving birth. In this manner one can assess if there is a danger of premature delivery $[8,9,10]$.

Researchers additionally propose that premature delivery rates can be brought down by enhancing the medical care for pregnant ladies during, after and before the pregnancy [11]. Thus, there is an essential requirement for continuously monitoring the health conditions of pregnant lady, having more risk factors, using HSN. This reduces the premature delivery $[12,13]$. Pregnant ladies with a high danger of premature delivery have to visit the medical center more frequently for monitoring their uterine contractions [11]. These visits may take days or even weeks, which makes the pregnant lady feel inconvenient. Therefore, any proposed way to deal with observing contractions of uterine ought to be consistent, home-comfy, practical, and with high reliability $[5,12]$. 


\section{WHSNs (Wireless Human Sensor Networks)}

Wireless human sensor networks (WHSNs) are new and evolving wireless networking technology. WHSNs have several specialized areas of applications in military, sport, entertainment, healthcare and industry. The WHSNs are able to monitor patients health continuously for reducing the risks that are involved in their health [14], as a result, the health and life period of the patient will definitely improve a lot [15].

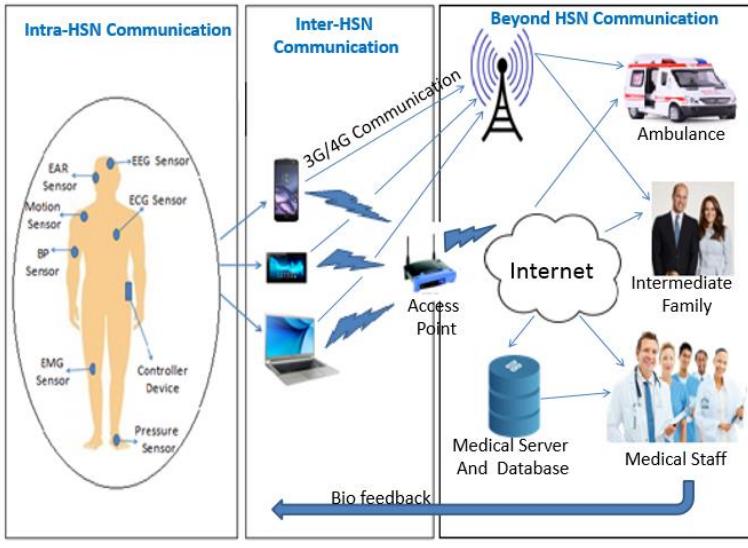

Fig.1 WHSN Architecture

The architectural design of WHSNs as shown in Fig. 1 comprises of several sensors which are placed on human body, receives and communicates important signals from the patient's body. A receiver medium gathers the signals from sensors \& examines patient's fundamental signs and passes that information to medical staff and family. A remote server is used for analyzing the data received from the receiver medium. It also stores the data received. WHSN has numerous number of advantages like minimal cost, versatility, safety, remote communication $[16,17]$ and the capacity to communicate with modern smart devices[18].

\section{Uterine Electro Hysterography (EHG)}

Utilizing the WHSN, electrohysterography (EHG) of the uterus can be recorded, for observing uterine contractions. EHG is measured in millivolts $(\mathrm{mV})$. EHG is the one best technique to monitor the contractions of the uterine in pregnant ladies. The intrauterine pressure (IUP) and tocodynamometer are the other techniques for monitoring the uterine contractions, but they are confined to the limitations [8]. Non-invasive reading is the most important benefits of EHG. It means that the sensor, without any difficulty, can be placed on the abdomen of a pregnant lady $[9,10]$, to measure the uterine muscle's electro-physiological signals The uterine muscle's electrical signals is converted to legible This technique converts the electrical activity of the uterine muscle into a readable tocogram [8]. The signals of EHG and IUP are highly correlated and when matched to external tocodynamometer, a high accurate uterine contractions reading is provided by the EHG $[8,10,11]$. EHG is more suitable for pregnant women when failed in external tocodynamometer [19]. In medical practice EHG provides a clearer tocographic waveform of uterine contractions. However, the quality of EHG signals is based on the suitable skin preparation and accurate placement of electrodes on abdomen of the pregnant lady. Hence with electrohysterography as noninvasive alternative for uterine monitoring, will be able to identify the incidence of normal and premature labor up to the pregnancy period of 27 weeks [20]. By utilizing WHSNs to gather EHG flags and examining them with a smart device, we can know if the pregnant lady is in the process of giving birth and alert her if required.

In this paper, a simple, safe and minimal cost framework has been proposed, to observe pregnant ladies who are at high danger of premature delivery. The proposed framework comprises of a WHSN to non-intrusively observe the uterine contractions and send an alarm signal or message using a modern smart device, when the danger is anticipated. It also proposed a proof-of-idea model and tried it for testing the performance, power utilization and quality of the system.

\section{Literature Survey}

A few investigations have been proposed for observing the health conditions of pregnant ladies as shown in Table1.

Table 1: Observations on monitoring pregnant ladies

\begin{tabular}{|c|c|c|c|}
\hline S. No & Proposed by & Features & Remarles \\
\hline 1 & $\begin{array}{l}\text { Z.Wang and } \\
\text { H. Jiang }\end{array}$ & $\begin{array}{l}\text { The authors } \\
\text { concentrated on sensors' } \\
\text { signal processing and } \\
\text { filtering techniques } \\
\text { [211. }\end{array}$ & $\begin{array}{l}\text { Focused on the technical side of } \\
\text { the system such as filtering } \& \\
\text { classifying signals from sensors } \\
\text { to improve the ouality of the data } \\
\text { received from these sensors. }\end{array}$ \\
\hline 2 & $\begin{array}{l}\text { WYang, } \\
\text { KYang } \\
\text { Jiang, and } \mathrm{Z} \\
\text { Wang }\end{array}$ & $\begin{array}{l}\text { The zuthors proposed a } \\
\text { fetal beart monitor } \\
\text { using a portable } \\
\text { stethoscope [22]. Their } \\
\text { system was an } \\
\text { extension of the system } \\
\text { proposed by [21]. }\end{array}$ & $\begin{array}{l}\text { Also focused on the technical side } \\
\text { of the system such as filtering \& } \\
\text { classifying gignals from sensors } \\
\text { to improve the ouality of the data } \\
\text { received from these sensors. }\end{array}$ \\
\hline 3 & $\begin{array}{l}\text { J. J. P. C. } \\
\text { Rodrigues, A } \\
\text { M } \\
\text { Oliveira, and } \\
\text { K. Saleem }\end{array}$ & $\begin{array}{l}\text { The authors proposed a } \\
\text { hesithcare rystem } \\
\text { using a Bayesian } \\
\text { model to support deci- } \\
\text { sion making for their } \\
\text { system [23]. }\end{array}$ & Same as the above two systems. \\
\hline 4 & $\begin{array}{l}\text { B. Vermeulen } \\
\text { Giovagnoli, } \\
\text { C. Paters, } \\
\text { M. B.vander } \\
\text { Hourvander } \\
\text { Jagt,MMisch } \\
\text { i, C. van Pul, } \\
\text { E. J. B. } \\
\text { Cottan, and } \\
\text { S. G. Oei }\end{array}$ & $\begin{array}{l}\text { The authors focused on } \\
\text { designing a tele- } \\
\text { monitoring system } \\
\text { called Nemo } \\
\text { Healthcare It monitors } \\
\text { the signals of fetal } \\
\text { heart rate, maternal } \\
\text { heart rate, uterine } \\
\text { contraction and fetal } \\
\text { electrocardiogram } \\
\text { [12]. The system sends } \\
\text { the signals wirelessly } \\
\text { to a server. }\end{array}$ & $\begin{array}{l}\text { The doctor monitors and } \\
\text { diagnoses the pregnant woman's } \\
\text { health status. It is expensive and } \\
\text { requires the physician to } \\
\text { contribute his ber time to } \\
\text { monitor the results. }\end{array}$ \\
\hline 5 & $\begin{array}{l}\text { A. Ni, M C } \\
\text { R I An-vida } \\
\text { end L. Stoicu- } \\
\text { tiveder }\end{array}$ & $\begin{array}{l}\text { The authors proposed a } \\
\text { system to monitor the } \\
\text { cardiotoco-graph } \\
\text { signals of the pregnant } \\
\text { womm [24]. The } \\
\text { system collects data } \\
\text { from the sensor } \\
\text { designed \& sends an } \\
\text { alarm to a smartphone. } \\
\text { The smart-phone then } \\
\text { sends alam to the } \\
\text { server system called } \\
\text { obGyn, where the } \\
\text { physician can monitor } \\
\text { the results at ary time }\end{array}$ & $\begin{array}{l}\text { This design is also expensive to } \\
\text { implement, and the physician must } \\
\text { contribute his/her time to monitor } \\
\text { the results. }\end{array}$ \\
\hline
\end{tabular}

\section{Proposed System}

Keeping in view the benefits of WHSNs and EHG, a system has been proposed by authors for continuously monitoring the conceived ladies having a high danger of premature delivery. The proposed system comprises of sensors and a smart device connected to those sensors. The sensors which are placed on the pregnant lady's belly as a non-intrusive strategy will uninterruptedly sense the EHG signs of the uterus and will transmit them to the connected smart device. The smart device will receive the signals from the sensors, will store them and will analyze the signals to understand the information. If the received information says that the readings are out of the acceptable range, immediately the smart device will send a warning signal or message. The proposed system is completely versatile and henceforth won't confine the pregnant lady from moving around openly.

This implies that the conceived lady can be observed remotely while she is in her home. She need not visit the medical center regularly. She can visit the medical center only when it is essential. In addition, the proposed system won't be costly to 
install and use, which implies that it is a reasonably cheap system even for the people of developing countries also. And there is no requirement for the doctor to spend his/her time to examine the patients.

\section{Implementation of proposed system}

The proposed system that has been introduced is a proof-ofidea application on Android OS (Operating System) which is a freeware. For the purpose of testing the developed application, the dataset of uterine contractions of conceived ladies in labor has been used. The dataset has been received from PhysioNet [25]. The dataset utilized was the Icelandic 16 - electrode EHG Dataset [26]. The dataset has a number of nearly $1,00,000$ uterine contraction values in $\mathrm{mV}$ of a pregnant lady in labor.

As the contraction detection threshold values differs from one patient to other patient [8], the application can be modified keeping in view the preferences of the patients that is determined by the medical surgeon. Depending on research outcomes of [8], the threshold value is chosen depending on false- positive rate. For example a value of $6 \mathrm{mV}$ has been chosen as a threshold value, to identify if the dataset contains a contraction or not. The false-positive rate of the threshold is chosen as $3.8 \%$. The proposed application persistently examines the database input to check if any uterine contraction greater than or equal to threshold value. Each observing session will keep going for half-an-hour [27]. In every repetition, the proposed application will tally uterine contractions for 10 minutes period.

Toward the finish of the half-an-hour duration, the application will find out the mean value of contractions by taking a count of the three 10 minutes time spans. In the event that the mean value is over 6 , an alert will be sent to the pregnant lady. Figure 2 demonstrates the flowchart for observing the uterine contractions and if required, sending a warning alert, where

$\mathrm{C}_{\text {num }} \rightarrow$ Total number of contractions,

$\mathrm{CT}_{\text {slot }} \rightarrow$ Decides whether the session completed 30 minutes time period,

$\mathrm{R} \rightarrow$ Reading that is retrieved,

Ts $\rightarrow$ Start time of every 10 minutes slot.

$\mathrm{Te} \rightarrow$ End time of every 10 minutes slot.

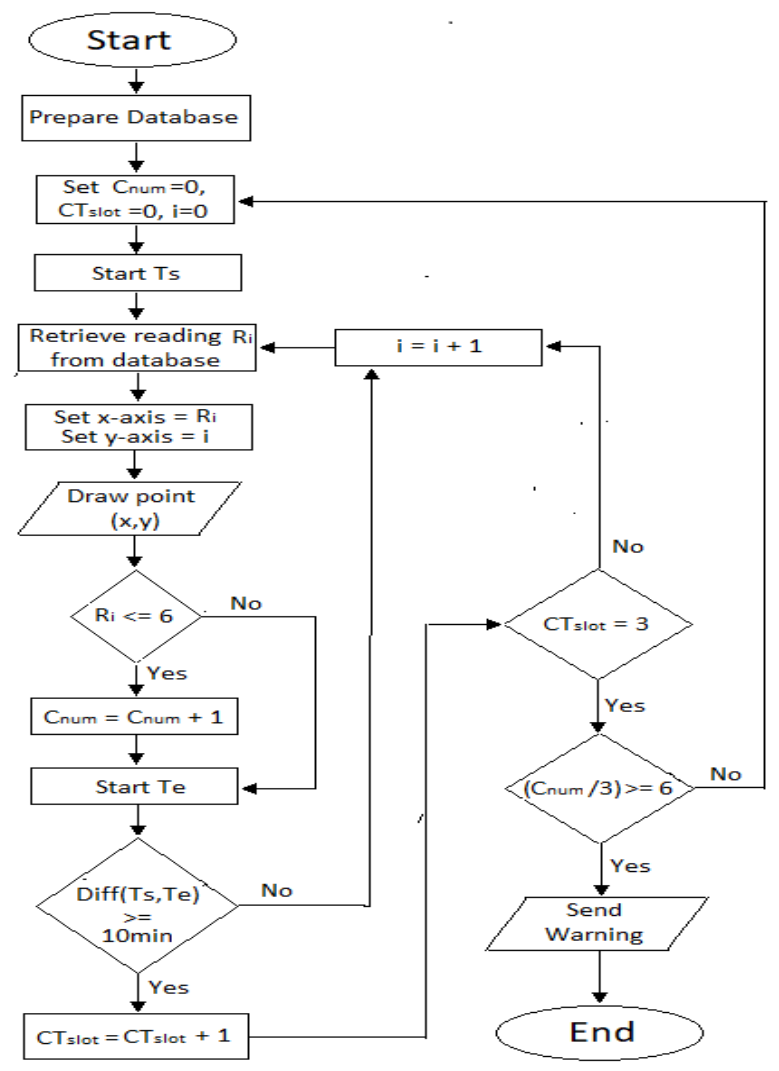

Fig. 2 Flowchart for observing the uterine contractions and sending a warning alert

\section{Performance Evaluation Results}

The proposed application is assessed based upon the CPU performance, Memory performance, power utilization and falsepositive rate of threshold value. During the testing process, the application was run for a duration of 30 minutes and a warning message is triggered at the end of the duration.

\subsection{Threshold and Contractions count}

The threshold value is chosen as $6 \mathrm{mV}$ in view of its falsepositive rate of $3.8 \%$. As is observed from Table-1, values lower than $6 \mathrm{mV}$ will bring about high contraction values, which will constantly give the warning alert even if there is no labor. With $6.1 \mathrm{mV}$, contractions number is less, which will not give any warning alert. That repudiates the database properties that show that the pregnant lady was in the process of giving birth at that time. Any threshold value that results in the value greater than $6.1 \mathrm{mV}$ shows a zero contraction count.

Table 2: Contractions count w.r.t. threshold value

\begin{tabular}{|c|c|}
\hline Threshold (mV) & $\begin{array}{c}\text { Count of Contractions from } \\
\text { the Application }\end{array}$ \\
\hline 6.3 & 0 \\
\hline 6.2 & 0 \\
\hline 6.1 & 17 \\
\hline 6.0 & 85 \\
\hline 5.9 & 904 \\
\hline
\end{tabular}




\subsection{CPU and Memory execution}

The proposed application utilizes an amount of $40 \%$ of the CPU-Power and allocates a memory of $27 \mathrm{MB}$ from an overall $2 \mathrm{~GB}$ of device memory.

\subsection{Power utilization}

The proposed application will be utilizing about $3 \%$ to $4 \%$ of the battery capacity of $3448 \mathrm{mAh}$.

\section{Discussion}

As has been discussed early, the threshold value varies from one pregnant lady to another pregnant lady. The analysis showed that $6 \mathrm{mV}$ has the ideal false-positive rate of $3.8 \%$ and that's the reason for choosing this value as a threshold value from the database. The proposed application runs easily with the $40 \%$ of CPU's utilized power. In addition, the application uses $27 \mathrm{MB}$ memory only.

At last, consumed power shows that the proposed application took just $3 \%$ to $4 \%$ of battery's charge. Assuming that the display screen was on all the time and the temperature of the device was ordinary, it can be concluded that the proposed application efficiently consumes the battery power.

\section{Conclusion}

Premature delivery of baby is entire world's problem that often causes the death of a child or may lead to the long lasting medical issues. The system proposed in this paper aims to lessen the issues related to the complications of premature deliveries by utilizing WHSNs. The WHSNs are used to observe the uterine contractions of the pregnant ladies and gives an alert message when it identifies the complications. The system proposed in this paper is assessed based upon the CPU performance, Memory performance, power utilization and false-positive rate of threshold value.

\section{References}

[1] World Health Organization. 2015. Preterm birth. (November 2015). Retrieved August 23, 2016 from http://www.who.int/ mediacentre/factsheets/fs363/en/

[2] A. Herbst and C. Nilsson, "Diagnosis of early preterm labour," BJOG An Int. J. Obstet. Gynaecol., vol. 113, no. SUPPL. 3, pp. 60$67,2006$.

[3] M. Zhang, V. Tidwell, P. S. La Rosa, J. D. Wilson, H. Eswaran, and A. Nehorai, "Modeling magnetomyograms of uterine contractions during pregnancy using a multiscale forward electromagnetic approach," PLoS One, vol. 11, no. 3, pp. 1-23, 2016.

[4] H. Ganer Herman, H. Miremberg, A. Dekalo, G. Barda, J. Bar, and M. Kovo, "Preterm uterine contractions ultimately delivered at term: Safe but not out of danger," Eur. J. Obstet. Gynecol. Reprod. Biol., vol. 199, pp. 1-4, 2016.

[5] P. S. La Rosa, H. Eswaran, H. Preissl, and A. Nehorai, "Multiscale forward electromagnetic model of uterine contractions during pregnancy.," BMC Med. Phys., vol. 12, p. 4, 2012.

[6] J. Karsdon, M. El Daouk, W. M. Huang, and G. G. Ashmead, "Electrical pacemaker as a safe and feasible method for decreasing the uterine contractions of human preterm labor," J. Perinat. Med., vol. 40, no. 6, pp. 697-700, 2012.

[7] A. López Bernal, "Overview. Preterm labour: mechanisms and management," BMC Pregnancy Childbirth, vol. 7, no. Suppl 1, p. S2, 2007.

[8] G. I. Bajlekov, C. Rabotti, S. G. Oei, and M. Mischi, "[7]- Electrohysterographic Detection of Uterine Contractions in Term Pregnancy," Embc, pp. 5851-5854, 2015.

[9] M. Liu, L. A. Belfore, Y. Shen, and M. W. Scerbo, "Uterine Contraction Modeling and Simulation," Comput. Methods Programs Biomed., vol. 107, no. 2, pp. 242-247, 2012.

[10] M. Lucovnik, Z. Novak-Antolic, and R. E. Garfield, "Use of Noninvasive Uterine Electromyography in the Diagnosis of Preterm Labour," Facts, views Vis. ObGyn, vol. 4, no. 1, pp. 66-72, 2012.

[11] M. Lucovnik, R. J. Kuon, L. R. Chambliss, W. L. Maner, S. Q.
Shi, L. Shi, J. Balducci, and R. E. Garfield, "Use of uterine electromyography to diagnose term and preterm labor," Acta Obstet. Gynecol. Scand., vol. 90, no. 2, pp. 150-157, 2011.

[12] B. Vermeulen-Giovagnoli, C. Peters, M. B. van der Hout-van der Jagt, M. Mischi, C. van Pul, E. J. E. Cottaar, and S. G. Oei, "The development of an obstetric tele-monitoring system," in 2015 37th Annual International Conference of the IEEE Engineering in Medicine and Biology Society (EMBC), 2015, pp. 177-180.

[13] L. F. Bastos, W. van Meurs, and D. Ayres-de-Campos, "A model for educational simulation of the evolution of uterine contractions during labor," Comput. Methods Programs Biomed., vol. 107, no. 2, pp. 242-247, 2012.

[14] H. Reza Naj and M. Aminian, "A Hospital Healthcare Monitoring System Using Wireless Sensor Networks," J. Heal. Med. Informatics, vol. 4, no. 2, pp. 4-9, 2013.

[15] R. Braojos, I. Beretta, J. Constantin, A. Burg, and D. Atienza, “A Wireless Body Sensor Network for Activity Monitoring with Low Transmission Overhead," 2014 12th IEEE Int. Conf. Embed. Ubiquitous Comput., pp. 265-272, 2014

[16] D. L. Carnì, G. Fortino, R. Gravina, D. Grimaldi, A. Guerrieri, and F. Lamonaca, "Continuous, real-time monitoring of assisted livings through wireless body sensor networks," Proc. 6th IEEE Int. Conf. Intell. Data Acquis. Adv. Comput. Syst. Technol. Appl. IDAACS'2011, vol. 2, no. September, pp. 872-877, 2011.

[17] H. Alemdar and C. Ersoy, "Wireless sensor networks for healthcare: A survey," Comput. Networks, vol. 54, no. 15, pp 2688-2710, 2010.

[18] R. Braojos, I. Beretta, J. Constantin, A. Burg, and D. Atienza, "A Wireless Body Sensor Network for Activity Monitoring with Low Transmission Overhead," 2014 12th IEEE Int. Conf. Embed. Ubiquitous Comput., pp. 265-272, 2014.

[19] Sangeeta Jain MD, Antonio F. Saad MD, Sanmaan S. Basraon MD, Comparing uterine electromyography \& tocodynamometer to intrauterine pressure catheter for monitoring labor, Journal Of Woman's Reproductive Health, vol. 1,no. 3, pp. 22- 30, 2016.

[20] Paul Fergus, Abir Hussian, D. Al- Jumeily, Hani Hamdan, "A machine learning system for automatic detection of preterm activity using artificial neural networks and uterine electromyography data", International Journal of Adaptive and Innovative Systems, vol. 2, no. 2,2015 .

[21] Z. Wang and H. Jiang, "Wireless intelligent sensor system for fetal heart rate tracing through body sound monitoring on a pregnant woman," 2013 IEEE MTT-S Int. Microw. Work. Ser. RF Wirel. Technol. Biomed. Healthc. Appl. IMWS-BIO 2013 - Proc., pp. 1-3, 2013.

[22] W. Yang, K. Yang, H. Jiang, and Z. Wang, "Fetal Heart Rate Monitoring System with Mobile Internet," pp. 443-446, 2014

[23] J. J. P. C. Rodrigues, A. M. B. Oliveira, and K. Saleem, "Smart Mobile System for Pregnancy Care Using Body Sensors," Int. Conf Sel. Top. Mob. Wirel. Netw. (MoWNeT)Short Pap., pp. 1-4, 2016.

[24] A. Ni, M. C. R. I. An-vida, and L. Stoicu-tivadar, "Integrated Wireless Sensor Network for Monitoring Pregnant Women," pp. 354-358, 2015.

[25] Goldberger AL, Amaral LAN, Glass L, Hausdorff JM, Ivanov PCh, Mark RG, Mietus JE, Moody GB, Peng C-K, Stanley HE. PhysioBank, PhysioToolkit, and PhysioNet: Components of a New Research Resource for Complex Physiologic Signals. Circulation 101(23):e215- e220 [Circulation Electronic pages: http://circ.ahajournals.org/cgi/ content/full/101/23/e215]; 2000 (June 13).

[26] Alexandersson, A., Steingrimsdottir, T., Terrien, J., Marque, C. Karlsson, B..The Icelandic 16-electrode electrohysterogram database. Sci. Data 2:150017 doi:10.1038/sdata.2015.17 (2015).

[27] K. R. Alden, D. L. Lowdermilk, M. C. Cashion, and S. E. Perry, Maternity and Women's Health Care. Elsevier Health Sciences, 2013. 